\title{
Alterations of the Cortical Representation of the Rat Ventrum Induced by Nursing Behavior
}

\author{
Christian Xerri, ${ }^{1}$ Judith M. Stern, ${ }^{2}$ and Michael M. Merzenich ${ }^{3}$ \\ 'Laboratoire de Psychophysiologie, Université de Provence, Faculté des Sciences de St Jérôme, 13397 Marseille cedex \\ 13, France, ${ }^{2}$ Department of Psychology, Rutgers University, New Brunswick, New Jersey 08903, and ${ }^{3}$ Keck Center for \\ Integrative Neurosciences and Coleman Laboratory, University of California at San Francisco, San Francisco, California \\ 94143-0732
}

The representation of the surfaces of the trunk was mapped in detail in a series of anesthetized adult female rats to assess cortical representational changes that might be induced in the SI cortical field by a major natural source of a differentially heavy schedule of tactile inputs: the stimulation of the rat ventrum in nursing behavior. Controls included virgin rats and postpartum age-matched rats whose litters were removed on the day of birth.

The SI representation of the ventral trunk skin of lactating rats was about $1.6 \times$ larger than in matched postpartum nonlactating or virgin controls. The greatest representational change-about twofold - was for the nipple-bearing skin between the forelimbs and hindlimbs. Indeed, changes in SI representational territory for the middle third of the ventrum, a skin zone without nipples, were not significant. As a rule, the representation of the ventrum skin in lactating rats was at least as topographically ordered as was that reconstructed for nonlactating postpartum and virgin controls.

Receptive fields (RFs) representing the ventrum skin in lactating females were about one-third the sizes of those recorded in matched nonlactating or virgin controls. RF size differences were again greater for the representation of the nipple-bearing skin in the anterior and posterior thirds of the ventrum than for the central third. Changes in RF sizes were roughly inversely related to changes in the cortical magnification of representation of the ventrum on the proportion of about 3:2. Interestingly, the glabrous nipple and areolar skin were only weakly represented-or not demonstrably represented-in the SI map of either lactating or control rats.

These results indicate that there is a largely unstudied cortical neurology of nursing behavior. Major CNS changes are induced by this dramatic, episodic change in behaviorally important tactile inputs. In turn, input-induced changes presumably contribute to this emergent, rapidly evolving behavior.

[Key words: somatosensory cortex, SI, lactation, maternal behavior, cortical plasticity, cortical barrels, rat]

Received March 15, 1993; revised Aug. 24, 1993; accepted Aug. 30, 1993.

This research was supported by NIH Grant NS-10414, NIH Grant MH-40459 (to J.M.S.), the Coleman Fund, and the CNRS-NSF. We thank Dr. William Jenkins, Christopher DeCharms, Bret Petersen, and Daniel Goldreich for their technical assistance in conducting these experiments.

Correspondence should be addressed to Dr. Michael M. Merzenich, Keck Center for Integrative Neurosciences, U-76, UCSF, San Francisco, CA 94143-0732.

Copyright (C) 1994 Society for Neuroscience $0270-6474 / 94 / 141710-12 \$ 05.00 / 0$
Nursing behavior constitutes an important natural example of a major time-marked change in regionally localized, behaviorally significant sensory inputs. In female rats, differential stimulation is initiated prior to parturition by the attending to and licking of the nipple skin (Roth and Rosenblatt, 1967), which contributes to mammary gland devclopment (Roth and Rosenblatt, 1968). Substantially greater input changes are incurred with the onset of nursing itself, which is initiated within an hour after the first pup is born (Rosenblatt and Lehrman. 1963; Holloway et al., 1980). During the first days postpartum, female Norway rats spend about $80 \%$ of their time nursing; nursing time progressively declines to about $25 \%$ by day 17 postpartum (Grola and Ader, 1969, 1974). Suckling stimulates neuroendocrine secretions necessary for milk secretion (prolactin) and milk release (oxytocin) (Tucker, 1988; Wakerley et al., 1988), as well as normal nursing behavior, including prolonged quiescence and the upright crouching posture (Stern and Johnson, 1990; Stern and Taylor, 1991; Stern et al., 1992). While the latter is reflexive (Stern, 1990) and while the female sleeps during much of the long daily nursing period (Stern and Levin, 1976; Voloschin and Tramezzani, 1979), there are numerous daily episodes of nursing initiation (Leon et al., 1978), and the lactating female is clearly alert at the onset of each nesting bout until suckling-induced quiescence occurs (Stern and Johnson, 1990; Stern et al., 1992).

A growing body of studies reveals that representational changes in the primary somatosensory cortical field(s) are induced by new tactual experiences in adult mammals (see Jenkins et al., 1990; Merzenich et al., 1990a,b; Recanzone et al., 1992a-c), including rats (e.g., Delacour, 1987; Kossut et al., 1988; Yun et al., 1989; Kossut, 1992; Welker et al., 1992). With heavy differential stimulation by moving or locationally inconstant tactile stimuli in adults, the zone of representation of the engaged skin within the primary somatosensory cortical field differentially expands (Yun et al., 1989; Jenkins et al., 1990; Merzenich et al., 1990a,b; Kossut, 1992). When moving tactile stimuli are applied in the behavior, inverse changes in receptive field (RF) sizes are concomitantly recorded (Jenkins et al., 1990). Thus, the differentially heavily stimulated skin comes to be represented over a larger cortical territory, and when the inputs are from nonstationary sources, in finer grain.

It is important to note that these positive changes arise only with attended behaviors, and that different changes result from associated inputs as compared with nonassociated inputs (Distcrhoft ct al., 1975; Woody and Engel, 1975; Weinberger and Diamond, 1988; Ahissar et al., 1992; Recanzone et al., 1992c,d). 
Moreover, when stimuli are delivered to rigidly fixed skin locations as compared with nonstationary skin locations, RFs can enlarge rather than contract in size (see Recanzone et al., 1992ac).

It is argued that these changes (Merzenich, 1990a,b; Recanzone et al., 1992c,d; Merzenich and Sameshima, 1993) parallel and account for emergent improvements in discriminative abilities. On the basis of these and many other observations, it has been concluded that the shaping of the details of cortical representations by new and constantly proportionately changing inputs occurs throughout life, with experiences thereby contributing a dynamic neurology to continually evolving behavioral capabilities and perceptions (Merzenich et al., 1984, 1988, 1990a,b; Edelman, 1987).

The major sensory input changes that occur with the initiation of nursing behavior represent a natural epoch in which cortical representational changes should be induced. Those induced changes, in turn, would be expected to contribute to this remarkable, rapidly evolving behavior. These present studies are designed to initiate the investigation of the neurological changes induced in one presumptively involved forebrain region, the "primary" skin surface representation in cortical area SI. Such studies are a starting point for reconstructing the panoply of distributed adaptive neurological changes that are hypothetically driven by - and account for the adaptive neurological aspects of - this complex behavior.

These experiments reveal that significant changes in the body surface representation are produced by nursing behavior. Those changes appear to arise from the heavy stimulation of the nipplebearing skin of the trunk ventrum that is generated in the behavior. These representational changes in SI constitute a hitherto undescribed contributor to this complexly emergent behavior.

\section{Materials and Methods}

Reported results are from 13 young adult female Long-Evans rats (Rattus norvegicus) weighing 220-360 gm (Simenson Laboratories, Gilroy, CA). Three control rats were virgins, approximately age matched with members of other rat groups. The other 10 females were primiparous, with cortical maps derived at different times after parturition. For four of these rats, designated "nonlactating," pups were removed from the mother on the day of birth and killed by an overdose of halothane gas. In these four controls, the cortex was mapped at days 12,14,16, and 18 postpartum. For five "lactating" mothers, nursing between 9 and 13 pups (mean $=10.6$ ), nursing behavior was unperturbed until the time of initiation of the cortical maps, which were derived at days $6,10,12$, 16 , and 19 postpartum. At those times, pups from these lactating females were killed as described above. In one additional demonstration rat, the cortex was mapped in a primiparous female 2.5 months after weaning following a 2 -week-long nursing period. The SI cortical maps derived in three of these 13 rats-one virgin, the $+6 \mathrm{~d}$ postpartum dam, and the postweaning female-were incomplete, although many data samples were derived in all three cases. Unless otherwise noted, the illustrated data are from the 10 rats in which cortical maps of the nipple-bearing ventrum skin were believed to be complete.

Treatment of rats was within the National Institutes of Health Guide for Care and Use of Laboratory Animals (revised 1987). Rats were initially anesthetized with halothane, and then intubated and anesthetized with sodium pentobarbital $(50 \mathrm{mg} / \mathrm{kg}$, i.v., for controls; $65 \mathrm{mg} / \mathrm{kg}$ for lactating dams). Anesthetic state was monitored by eye-blink and paw-withdrawal reflexes, and supplemental doses of diluted sodium pentobarbital were intravenously administered throughout the course of the experiments to maintain animals at an areflexive level of anesthesia. The rats were given a single dose of atropine sulfate $(0.1 \mathrm{mg} / \mathrm{kg}$, i.m.) to suppress respiratory secretions. Body temperature was monitored and maintained between $36^{\circ} \mathrm{C}$ and $38^{\circ} \mathrm{C}$. Rats were killed at the end of each recording experiment by administration of an overdose of sodium pentobarbital.

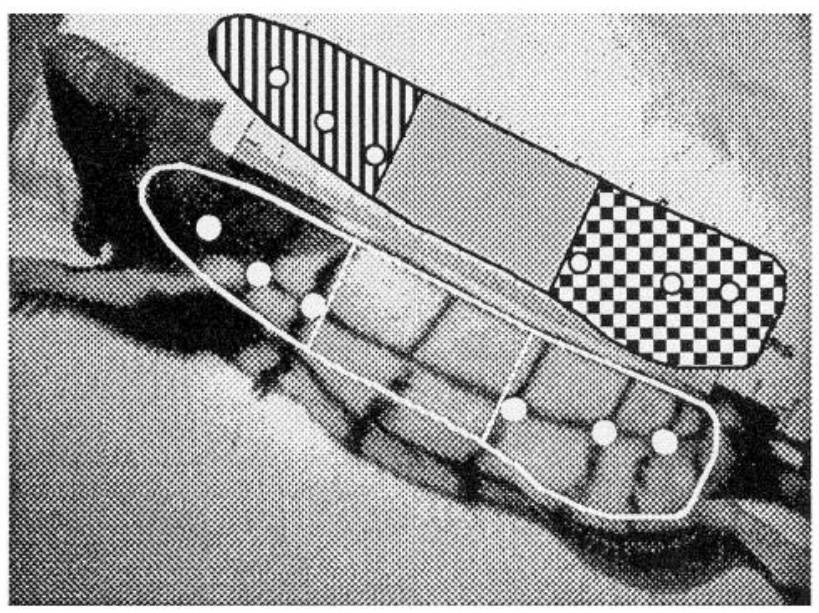

Figure 1. The skin designated as the "ventrum" of the female rat is outlined in white in this typical computer image taken as part of a cortical mapping experiment. Grid lines marked by indelible ink were used to facilitate the accurate drawing of cutaneous RFs. In the analyses described in Results, the ventrum skin was separated into thirds, as indicated. The anterior and posterior each bear three of the six nipples (white dots) on the mapped side of the ventrum. Ventrum designations in the drawing above match those used in the reconstructions of the ventra in 10 female rats, in Figure 3.

Long hairs on the trunk were trimmed to facilitate the subsequent estimation of cutaneous RF boundaries. After marking the body surface with indelible grid lines connecting the nipples or oriented orthogonal to them, the surfaces of the trunk contralateral to the exposed cortex were imaged using a Cohu CCD video camera and framegrabber and IMAGE software, in each experiment (e.g., see Fig. 1). The rat was then mounted in a headholder in a stereotaxic frame that provided easy access to the surfaces of the trunk contralateral to the cerebral hemisphere to be mapped. After tracheal cannulation and cerebrospinal fluid drainage through an opening in the foramen magnum, the somatosensory cortex was exposed by a surgical craniotomy. The dura was resected and the directly exposed cortex bathed in a pool of 20 centistoke dimethylpolysiloxane. A $40 \times$ computer image of the cortical surface vasculature was then obtained through a Zeiss operating microscope mounted with a beamsplitter and the video camera.

Neuronal responses were recorded from units or small clusters of units by the use of parylene c-insulated tungsten microelectrodes with impedances of about $1.5 \mathrm{M} \Omega$ at $1 \mathrm{kHz}$. At each of 45-135 sample sites, microelectrodes were advanced normal to the cortical surface to a target depth of approximately $750 \mu \mathrm{m}( \pm$ about $50 \mu \mathrm{m})$. The position of electrode entry into the brain was recorded on the magnified computer image of the brain surface stored by use of multiple-layer caNVAs software, by reference to the details of the cortical surface vasculature. In all experiments, sample sites were separated by about $80-200 \mu \mathrm{m}$. Equivalent sampling densities were applied in experimental and control cases. All penetrations in any given experiment were parallel.

Receptive fields were defined as those areas of skin at which hair deflection or just-visible skin indentation produced with a fine glass probe evoked a reliable neural discharge, as previously described (Merzenich et al., 1984; Stryker et al., 1987). These skin fields were drawn on the computerized images of the body surface. The grid pattern marked on the fur of the rat with insoluble ink and the mottled colored fur patches on these Long-Evans rats' trunks (Fig. 1) served as guides for accurately drawing RFs on the body surface. The three dimensions of these body surface reconstructions were taken into account at the time of RF definition.

When RFs extended over the nipple skin, it was probed with light tactile stimulation as well as with heavier taps and, in some cases, suction stimuli. In general, as is noted below, low-threshold responses were rarely evoked by nipple or areolar stimulation in these experiments.

Construction of cortical "maps". Representations of different surfaces of the rat trunk were reconstructed in each experiment. The "ventrum" of the rat was defined as the skin zone extending from the midline to a 


\section{A NOn-Lactating RAt (18 Days Postpartum)}
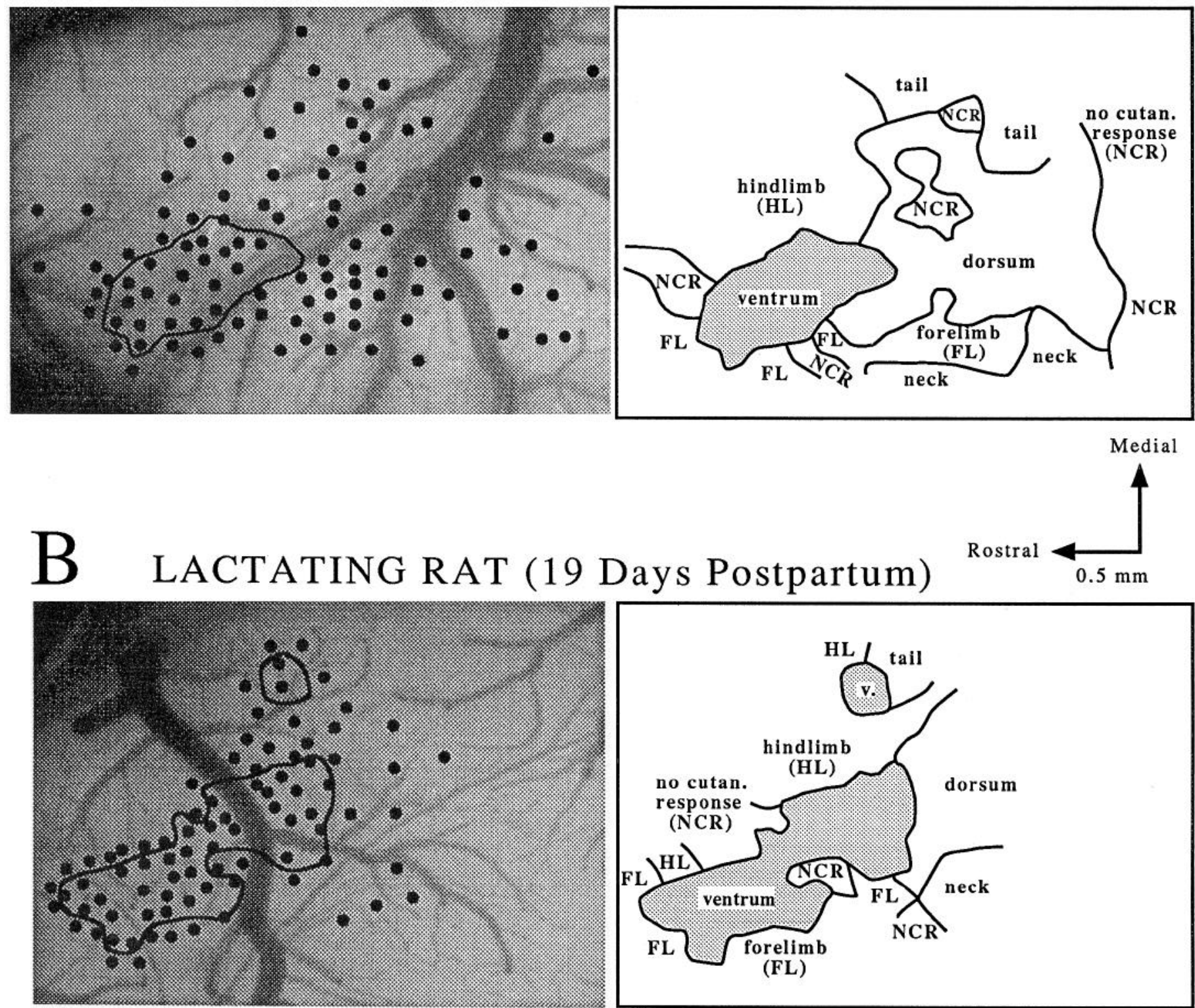

Figure 2. Mapping and reconstruction procedures used to produce maps of the skin surfaces of the trunk. Left, magnified computer image of the surface of a limited sector of the primary somatosensory (SI) cortical field in a $+18 \mathrm{~d}$ postpartum primiparous nonlactating control rat $(A)$, and in a +19 d postpartum primiparous lactating rat $(B)$. Black dots mark microelectrode penetration sites at which RFs were defined for neurons or small clusters of neurons in the middle cortical layers in the trunk (and surrounding) representational sector(s) of the SI cortex. Heavy dark lines outline the estimated zones of representation of the trunk ventra. Right, cartoon reconstructions of these two representative mapping experiments. The estimated zones of representation of the ventra are shaded. Bordering cortical zones represent the skin of the forelimb $(F L)$, hindlimb $(H L)$, neck, tail, and dorsum. In regions labeled "not cutaneous" $(N C R)$, neurons were not excited by light tactile stimulation, as is typical for significant SI sectors in a zone(s) neighboring the trunk representation (see Welker, 1971; Chapin et al., 1985, 1990).

distance lateral to the nipples equal to half the distance from the midline to the nipple, and included the skin flanking the posteriormost nipples on the inner surface of the thigh. This "ventrum" skin is illustrated by example in Figure 1. With the development of the mammae in nursing, the total area of the ventrum skin was modestly larger in lactating females $\left(59.8 \pm 6.7 \mathrm{~cm}^{2}\right)$ than in nonlactating postpartum controls $(50.8$ $\left.\pm 6.1 \mathrm{~cm}^{2}\right)$, and more substantially larger than in approximately agematched virgin $\left(40.3 \pm 3.8 \mathrm{~cm}^{2}\right)$ controls. Approximately proportional differences in overall body weight were recorded between these three roughly age-matched female rat groups.

To reconstruct the cortical representations of the ventrum, the re- mainder of the trunk skin ("dorsum") and of surrounding body surfaces, cartoon maps were drawn by bounding the cortical sites at which the RFs of neurons were centered on different skin surfaces. Examples of such map reconstructions are shown in Figure 2.

Cortical representational areas and cutaneous RF areas were determined by the use of measurement software in the program CANVAs (Deneba). RFs were defined by their absolute areas, and with normalization as a function of the total "ventrum" skin surface area measured in each individual rat. Statistical comparisons were performed using an analysis of variance (ANOVA) completed with the Fisher PLSD post hoc test (STATVIEW II). 

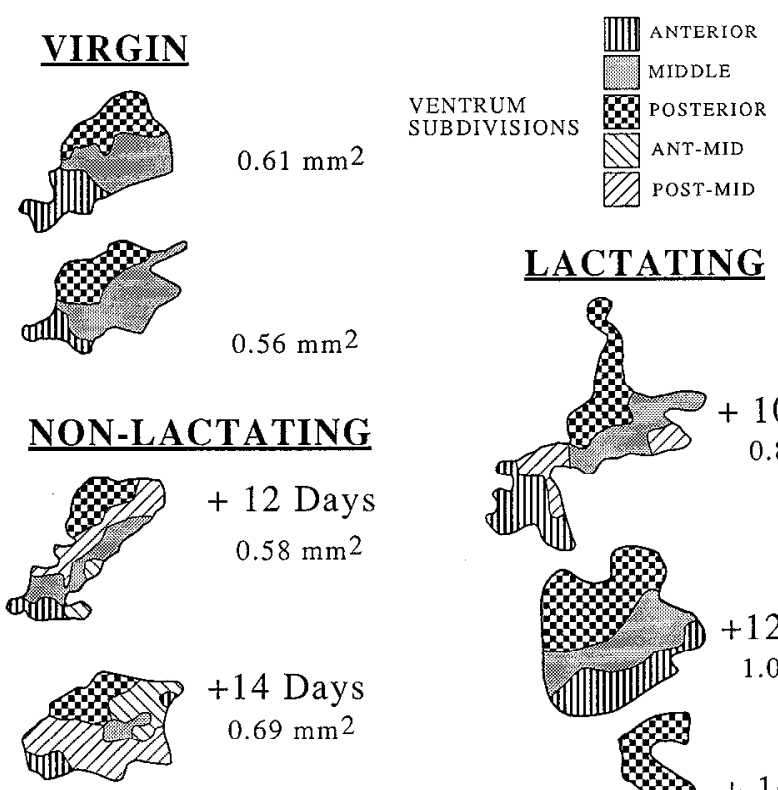

\section{LACTATING}
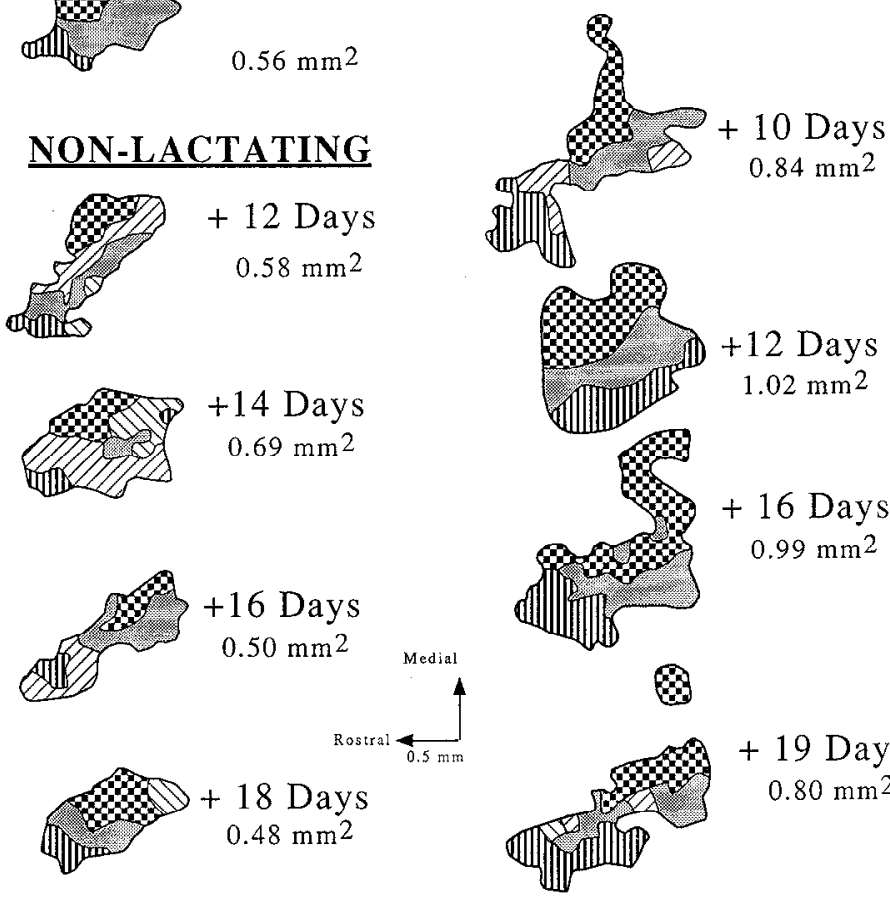

+19 Days $0.80 \mathrm{~mm}^{2}$

Figure 3. Reconstructed ventrum representations from 10 rat cases. Two maps from virgin rats are shown at the upper left; four from postpartum nonlactating rats at the lower left; and four from postpartum lactating rats in the right column. See Figure 1 and the text for the definition of "ventrum" skin. In ventrum map cartoons, SI representational territories in which RFs were centered on the anterior (vertical stripes), middle (stippled), or posterior (checkerboard) ventrum thirds are distinguished in each drawing. As shown in the key at the top, zones over which neurons had RFs with nearly equal parts on two of these three skin surfaces are indicated by diagonal hatching. In cortical representational areal measures, these zones were divided equally between the bordering skin regions that RFs broadly overlapped. Total ventrum representational areas are shown at the right of each cartoon drawing. Note that the SI ventrum representations were consistently larger in lactating rats that in controls. See text for further details.

\section{Results}

Maps of the representation of the trunk ventrum are shown for representative postpartum lactating and nonlactating female rats in Figure 2. Penetration sites are shown with reference to the cortical surface vasculature in the panels at the left. Territories of representation of the ventrum skin (see Fig. 1) are outlined. The location of the outlines between sample sites reflects the proportional part of the RF that overlays the ventrum and other bordering, designated skin surfaccs. Notc that all reported ventrum maps were bounded by samples in which neurons were predominantly driven by stimulation of other skin surfaces. In these two typical examples, ventrum representation zones in SI were directly flanked by 22 and 36 penetrations in which RFs were located predominantly on other skin surfaces. With many boundary site definitions as in these cases, a relatively accurate estimation of the territories of representation of the ventrum was obtained (see Stryker et al., 1987).

\begin{tabular}{|c|c|c|c|c|c|c|c|}
\hline & $10 \mathrm{~d}$ & $12 \mathrm{~d}$ & $14 \mathrm{~d}$ & $16 \mathrm{~d}$ & $18 \mathrm{~d}$ & $19 \mathrm{~d}$ & Mean \pm SD \\
\hline \multicolumn{8}{|c|}{ Nonlactating } \\
\hline $\mathrm{A}^{a}$ & - & 0.08 & 0.20 & 0.12 & 0.08 & - & $0.12 \pm 0.06$ \\
\hline M & - & 0.27 & 0.27 & 0.28 & 0.17 & - & $0.25 \pm 0.05$ \\
\hline \multirow[t]{2}{*}{$P$} & - & 0.23 & 0.22 & 0.10 & 0.23 & - & $0.19 \pm 0.06$ \\
\hline & - & 0.58 & 0.69 & 0.50 & 0.48 & - & $0.56 \pm 0.10$ \\
\hline \multicolumn{8}{|c|}{ Lactating } \\
\hline A & 0.29 & 0.28 & - & 0.26 & - & 0.28 & $0.28 \pm 0.01$ \\
\hline $\mathbf{M}$ & 0.30 & 0.32 & - & 0.29 & - & 0.21 & $0.28 \pm 0.05$ \\
\hline \multirow[t]{2}{*}{$\mathbf{P}$} & 0.25 & 0.42 & - & 0.44 & - & 0.31 & $0.35 \pm 0.09$ \\
\hline & 0.84 & 1.02 & - & 0.99 & - & 0.80 & $0.91 \pm 0.11$ \\
\hline \multicolumn{8}{|c|}{ Virgin } \\
\hline A & 0.16 & 0.07 & - & - & - & - & $0.12 \pm 0.06$ \\
\hline $\mathbf{M}$ & 0.25 & 0.31 & - & - & - & - & $0.28 \pm 0.04$ \\
\hline \multirow[t]{2}{*}{$\mathrm{P}$} & 0.20 & 0.18 & - & - & - & - & $0.19 \pm 0.01$ \\
\hline & 0.16 & 0.56 & - & - & - & - & $0.59 \pm 0.04$ \\
\hline
\end{tabular}

Cartoon drawings illustrating functionally defined cortical representational zones are shown at the right of each drawing in Figure 2 . The ventrum representation is flanked posteriorally by a large representation of the "dorsum" (lateral and dorsal surfaces) of the trunk. Hindlimb, forelimb, and noncutaneous response zones also commonly bordered the ventrum representation (see Welker, 1971, 1976; Chapin and Lin, 1984, 1990). The actual skin surfaces across ventrum borders and the lengths of these border segments were highly variable in different mapped females in all rat series.

\section{Cortical area of representation of the ventrum in primiparous lactating versus primiparous nonlactating and virgin rats}

Cartoon drawings outlining the territories of representation of the ventrum are illustrated for 10 rats in Figure 3 . In those drawings, representational territory is subdivided with respect to whether RFs were centered over the anterior third, the middle third, or the posterior third of the trunk ventrum (see Fig. 1 for this tripartite ventrum division; see Fig. $3 \mathrm{key}$, top right). In Figure 3, (1) maps from two virgin rats are shown at the upper left, (2) maps from four nonlactating rats are shown in the lower left column, and (3) maps from four lactating rats are shown in the column at the right.

The SI territories of representation of the ventrum for virgin and for roughly age-matched postpartum nonlactating rats were approximately identical in size (mean $\pm \mathrm{SD}=0.59 \pm 0.04$ vs $0.56 \pm 0.10 ;$ see Table 1$)$. On the other hand, the SI territory of representation of the ventrum was, on the average, about $1.6 \times$ larger in lactating than in control rats. This difference between lactating rats versus both virgins and nonlactating primiparous controls was significant at the $p<0.006$ level $[F(2,7)$ $=15.43]$.

When the cortical territories of representation of the anterior and posterior nipple-bearing ventrum thirds and the central third devoid of nipples were distinguished, it was evident that the differences between zones of cortical representation in lactating versus control rats occurred only for the former (Fig. 4). Thus, the representation of the nipple-bearing anterior ventrum was about $2.3 \times$ larger on average than for controls; the nipplebearing posterior skin was about $1.8 \times$ larger. Differences be- 


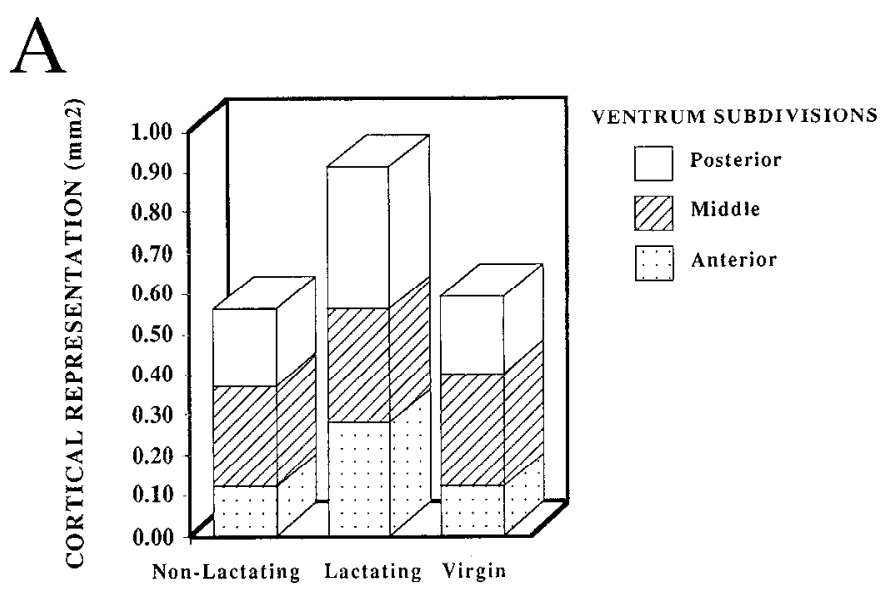

B

\begin{tabular}{|c|c|c|c|}
\hline & $\begin{array}{c}\text { Non } \\
\text { Lactating }\end{array}$ & Lactating & Virgin \\
\hline Anterior & $0.12 \pm 0.06$ & $\begin{array}{l}0.28 \pm 0.01 \\
0.005\end{array}$ & $\begin{array}{l}0.12 \pm 0.06 \\
0.005\end{array}$ \\
\hline Middle & $0.25 \pm 0.05$ & $0.28 \pm 0.05$ & $\begin{array}{l}0.28 \pm 0.04 \\
\mathrm{n}_{\mathbf{L}} \mathrm{s} .\end{array}$ \\
\hline Posterior & $0.19 \pm 0.06$ & $\begin{array}{l}0.35 \pm 0.09 \\
0.005\end{array}$ & $\begin{array}{l}0.19 \pm 0.01 \\
0.005\end{array}$ \\
\hline TOTAL & $0.56 \pm 0.10$ & $\begin{array}{l}0.91 \pm 0.11 \\
0.005\end{array}$ & $\begin{array}{l}0.59 \pm 0.04 \\
0.006\end{array}$ \\
\hline
\end{tabular}

Figure 4. A, Mean areas of representation of the posterior, middle, anterior, and total ventrum surfaces for postpartum nonlactating, lactating, and age-matched virgin rats. $B$, Group (mean $\pm \mathrm{SD}$ ) statistics for these three experimental series. Significance levels are indicated by arrows; n.s., no significant difference.

tween lactating rats and all controls were significant at the $p<$ 0.005 level $[F(2,27)=8.85]$. By contrast, while larger on the average in these small series, the SI territories of representation of the nipple-devoid middle third of the ventrum (see the inset, Fig. 3) in lactating rats did not differ significantly from that recorded in either control group (Fig. 4B).

\section{Evidence for continuous topographic expansion of a shifting-} overlap representation of the ventrum in lactating rats

The internal shifting-overlap topographic order of RFs representing the ventrum skin was not obviously different in lactating females as compared with control rats (Fig. 5). That is, RFs generally shifted continuously as penetrations moved across the cortex in any direction, as in the representative examples in Figure 5, with the representation of the extreme margins of the ventrum skin located at the extreme margins of the SI ventrum zone. For example, RFs representing the skin along the midline were invariably arrayed along the far rostral border of the SI ventrum zone, RFs bordering the more dorsal trunk were invariably represented caudolaterally, the skin over the anterior trunk in front of the forelegs was represented at the anterior extreme of the ventrum zone, and the perivaginal skin was represented in the extreme medial or rostromedial zone. Thus, in its apparently larger form in lactating females, there was still a simple, single, orderly representation of the ventrum skin in SI.

As the ventrum representation enlarged, what other skin surfaces likely lost SI representational territory? Chronic recording experiments in rats carried through parturition and nursing would have to be conducted to resolve this issue with certainty. How- ever, examination of bordering skin surfaces in both control groups and in nursing rats indicates that in different rats, zones of representation of the nipple-bearing ventrum zones between the forelegs and hindlegs border the zones of representation of forelimb and hindlimb skin, as well as the zone of representation of the trunk dorsum, and an SI zone(s) in which responses were not cutaneous. With representational expansion apparently consequent from suckling, ventrum representations in some rats appear to widen, others appear to elongate, or both changes occur. Fncroachment of the expanding representation across all of its bordering representational zones would appear to be possible.

It has long been argued that there is a general correspondence between SI layer 4 "anatomical maps" of the body surface of the rat and the physiologically defined body surface specificity of recorded neuronal responses (see Welker, 1976). The present results indicate either that nursing-induced changes create a discordance between layer 4 "anatomical maps" of the body surface and functionally defined maps of these skin surfaces, or, alternatively, that a parallel change in the layer 4 "anatomical map" is induced by this behavior. Directly correlated anatomical and physiological studies must be conducted to resolve which of these interesting possibilities actually applies.

\section{Sizes and distributions of RFs in lactating versus control rats}

RFs reconstructed from neuronal response samples in the ventrum representational zone in lactating rats were smaller than were those recorded in control populations. All ventrum RFs from a representative cortical map taken from each of these short series are shown in Figure 6 . There, the ventrum skin is outlined by a heavy black line; nipples are indicated by small dark circles; cutaneous receptive fields are outlined by thinner black lines. As in all such cases, differences in the sizes and regional distributions of RFs are evident at a glance. In these representative cases, the absolute skin areas of RFs averaged $10-11 \mathrm{~cm}^{2}$ in both control maps (Fig. $6 A, C$ ), while they averaged $3.8 \mathrm{~cm}^{2}$ in the lactating rat (Fig. $6 B$ ). Moreover, small RFs were recorded in larger numbers in the more anterior and more posterior aspects of the ventrum skin in the lactating case.

The difference in the representation of the anterior and posterior nipple-bearing skin regions as compared with the nippledevoid central ventrum sector is illustrated in another way in Figure 7. There, the numbers of RF samples were sorted as a function of the anterior-posterior position of their RF centers, for five lactating and for four postpartum nonlactating control rats. There was a clear bias for the representation of nipplebearing skin between the hindlimbs and forelimbs of lactating females, but not in nonlactating controls. Dispersions of samples across the skin in virgin rats did not obviously differ from those in postpartum nonlactating rats.

When ventrum RF area data were compared for these different small female rat populations (Fig. $8 A$, Table 2 ), on average: (1) RFs were $2.3 \times$ smaller in lactating [4.88 $\pm 3.33(\mathrm{SD}) \mathrm{cm}^{2}$ ] than in virgin rats $\left(11.45 \pm 6.16 \mathrm{~cm}^{2}\right)[F(2,329)=101.99, p<$ $0.00001)$ ], (2) RFs were $2.8 \times$ smaller in lactating than in approximately matched nonlactating postpartum females (13.92 $\left.\left.\pm 7.08 \mathrm{~cm}^{2}, p<0.00001\right)\right]$, while (3) areas of RFs were smaller in virgin than in nonlactating controls $(p<0.05)$.

It was noted earlier that with the development of the mammae, the overall surface area of the ventrum was modestly greater in lactating than in nonlactating rats, and was greater in both lactating and nonlactating rats than in virgin controls. To com- 


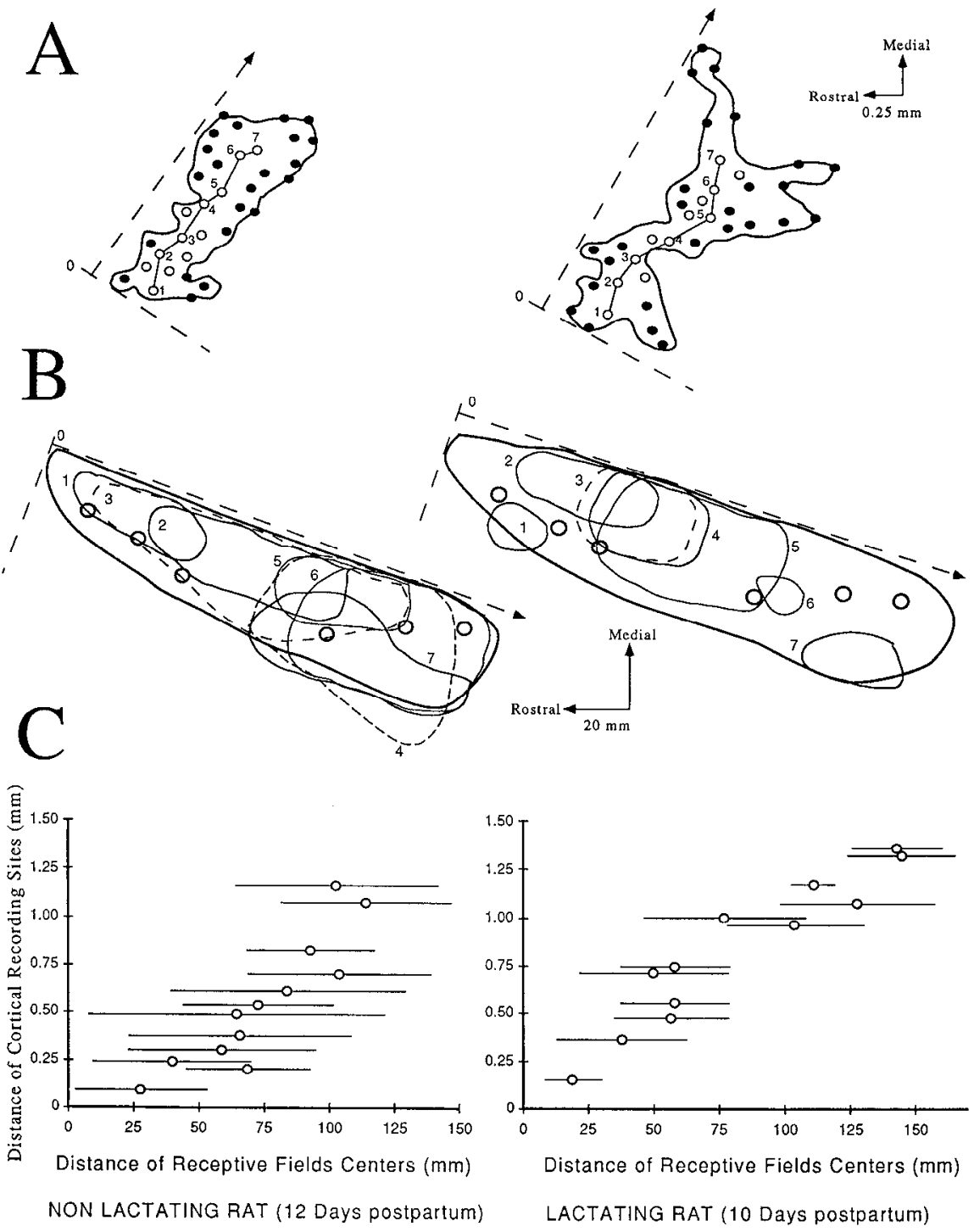

Figure 5. Representative RF sequences from maps derived in postpartum nonlactating (left) and lactating (right) rats. Note that only a fraction of the cortical response sampling sites for these maps are indicated in these cartoons. As penetration sites shifted across the SI ventrum representational zone $(A)$, RFs almost always shifted in an orderly, continuous shifted-overlap progression across the rat ventrum $(B)$, in all experimental cases. In $C$, the rostrocaudal extent of each RF is represented by a horizontal bar to more clearly show the extents of RF overlaps in this typical RF progression. pensate for these differences in physical skin expansion, RF data for the three rat populations were normalized by reference to the total measured ventrum skin surface in each individual, as shown in Figure $8 B$. With normalization, differences in RF areas in lactating versus control populations were even greater $(3.3 \times$; $p<0.00001$ ). On average, RFs in lactating rats occupied $8.5 \%$ of the ventrum surface, as compared with $28.1 \%$ and $28.6 \%$ of the ventrum surface in nonlactating and virgin controls. Note

Table 2. Receptive field sizes

\begin{tabular}{|c|c|c|c|c|c|c|c|c|}
\hline & $6 d$ & $10 \mathrm{~d}$ & $12 \mathrm{~d}$ & $14 \mathrm{~d}$ & $16 d$ & $18 \mathrm{~d}$ & $19 \mathrm{~d}$ & $\begin{array}{l}\text { Total } \\
\text { population }\end{array}$ \\
\hline \multicolumn{9}{|c|}{ Nonlactating } \\
\hline $\mathrm{cm}^{2}$ & - & - & $14.86 \pm 6.86$ & $12.37 \pm 6.79$ & $10.86 \pm 6.29$ & $17.56 \pm 7.10$ & - & $13.92 \pm 7.08$ \\
\hline$\%$ & - & - & $33.76 \pm 15.45$ & $25.77 \pm 14.15$ & $20.84 \pm 12.06$ & $30.23 \pm 12.23$ & - & $28.07 \pm 14.37$ \\
\hline$n$ & - & - & 28 & 29 & 19 & 21 & - & 97 \\
\hline \multicolumn{9}{|c|}{ Lactating } \\
\hline $\mathrm{cm}^{2}$ & $3.59 \pm 2.00$ & $7.92 \pm 4.70$ & $4.20 \pm 1.62$ & - & $3.81 \pm 2.36$ & - & $5.29 \pm 3.25$ & $4.88 \pm 3.33$ \\
\hline$\%$ & $7.99 \pm 4.44$ & $12.19 \pm 7.24$ & $7.27 \pm 2.81$ & - & $7.47 \pm 4.63$ & - & $8.04 \pm 4.94$ & $8.54 \pm 5.28$ \\
\hline$n$ & 36 & 32 & 27 & - & 43 & - & 34 & 172 \\
\hline \multicolumn{9}{|l|}{ Virgin } \\
\hline $\mathrm{cm}^{2}$ & $10.27 \pm 6.21$ & $11.02 \pm 5.41$ & $12.76 \pm 7.14$ & - & - & - & - & $11.45 \pm 6.16$ \\
\hline$\%$ & $23.94 \pm 14.48$ & $30.61 \pm 15.04$ & $30.46 \pm 17.04$ & - & - & - & - & $28.65 \pm 15.45$ \\
\hline$n$ & 24 & 23 & 18 & - & - & - & - & 65 \\
\hline
\end{tabular}




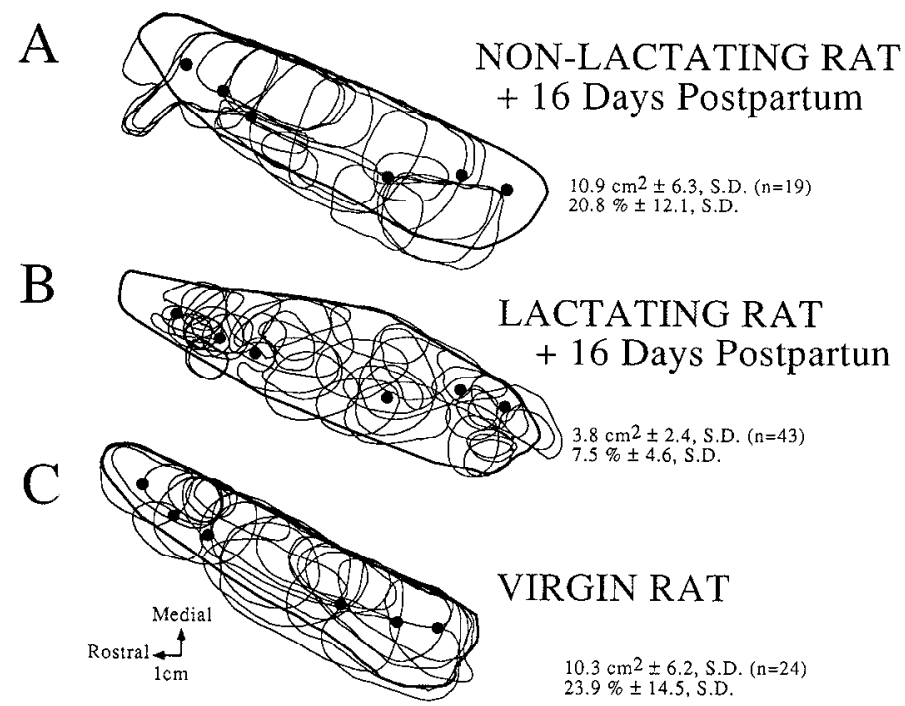

Figure 6. All RFs defined in the SI ventrum representational zone in a representative postpartum nonlactating rat $(A)$, lactating rat $(B)$, and virgin rat $(C)$. The heavy dark lines outline the ventrum skin; small solid circles mark the locations of nipples; thinner lines outline cortically recorded cutaneous receptive fields. The means and SDs of measured and normalized (with reference to total ventrum skin area) RF sizes are shown for each case, at the right.

that after normalization, the mean RF sizes and dispersions for the two control groups were virtually identical.

\section{Differences in RF sizes for anterior, middle, and postcrior ventrum representation sectors}

As with cortical representational area, differences in RF sizes between lactating and control group samples were greater for the nipple-bearing anterior and posterior ventrum representational zones than for the representation of the nipple-devoid middle zone (Fig. 9). RFs in the ventrum skin between both the forelegs and hindlegs of lactating rats were about one-third the size in lactating rats than in nonlactating postpartum rats, while those for the middle third in lactating females were a little more than one-half as large. Differences between RFs from all three ventral zones in lactating rats and controls were significant at the $p<0.001$ level $[F(5,166)=33.80]$. As is evident, for example, in the RF drawings in Figure 6, RFs for both the anterior and posterior regions were significantly smaller than were those for the central nipple-devoid skin sector (Fig. 9B).

\section{Relationships between cortical magnification and RF sizes}

In some other examples of cortical remodeling with experience or after peripheral lesions, cortical magnification (cortical area/ skin surface area) appeared to increase as an approximately inverse function of the change in RF sizes (see Merzenich et al., 1984, 1985; Jenkins et al., 1990), suggesting that a "hypercolumn rule" might be actively maintained in the cortex (see Hubel and Wiesel, 1974; Sur et al., 1985). In accordance with a hypothetical "hypercolumn rule," any given RF would bc rcprcsented over an approximately constant-sized cortical area (a cortical "hypercolumn"), regardless of RF size.

In plotting cortical magnification against RF size in the present experiments, it is necessary to compensate for the ballooning of the skin accompanying mammary development in the estimation of both cortical magnification and RF size (Fig. 10).
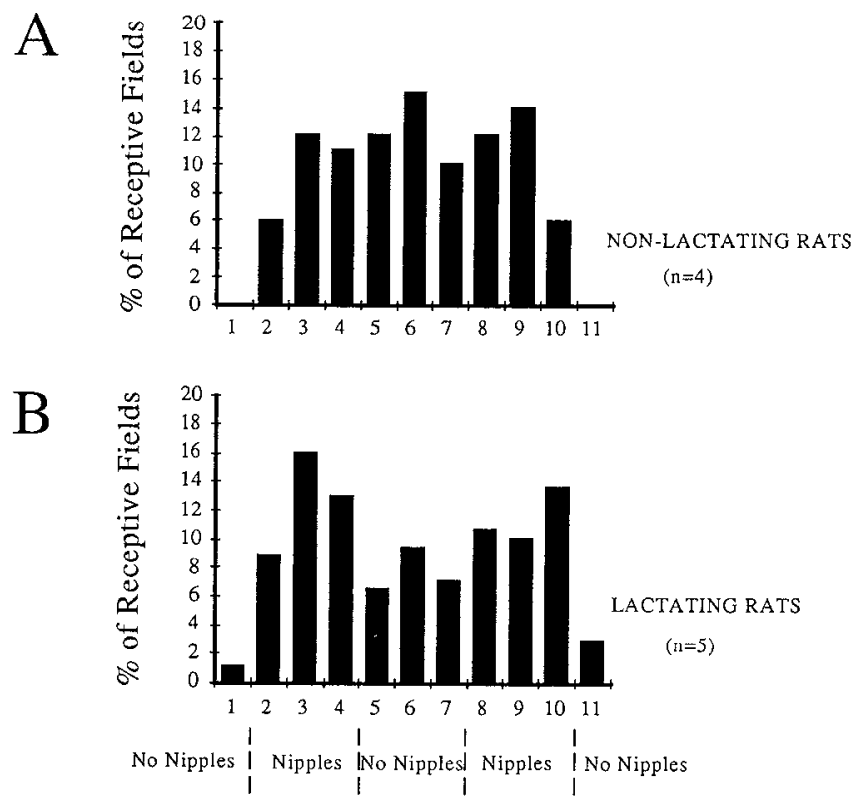

Figure 7. Percentage of all recorded SI ventrum RFs sorted as a function of the locations of RF centers along the rostrocaudal dimension of the ventrum skin. Data are from four nonlactating postpartum control rats $(A)$ and from five postpartum lactating rats (including the $+6 \mathrm{~d}$ rat) $(B)$.

With compensation for this skin expansion, an inverse relationship with an approximate proportion of $3: 2$ between cutaneous RF sizes and cortical magnifications was recorded. That is, although cortical magnification and RF size appeared to be systematically related, a strict "hypercolumn rule" requiring a 1:1 proportionality was not maintained during these representational changes. This observation-especially taken with results in studies of Recanzone et al. (1992b) in which RF changes were generated that are proportionally greater than cortical areal representational changes - indicates that a cortical magnification/RF size "hypercolumn rule" is not strictly maintained during representational remodeling by the cortical machine, as was earlier hypothesized (see Merzenich, 1983, 1984a,b).

\section{Nonexistent or limited representation of the nipple and areolar} skin in SI cortex

RFs often completely encircled one (occasionally, more than one) nipple(s). The skin surfaces on the nipples of lactating rats are substantial, as they extend to lengths of more than a centimeter in suckling. Moveover, the glabrous areolar skin surrounding each nipple was relatively large in nursing females, especially when compared with virgin controls. When RFs extended across the hairless skin of the nipple and areola, those skin surfaces were explored with light tactile stimulation. With a handful of possible exceptions from more than 100 such samples, responses are not evoked from this skin by light tactile stimulation, while single units at these same cortical sites were commonly exquisitely sensitive to deflection of the hairs surrounding the areolar skin.

It might be noted that while we also applied heavier stimuli including nipple suction in mapping RFs in several rats, we did not apply such stimuli consistently, and we did not investigate responsiveness of these neurons to suckling per se. In fact, our neuron sample would be excited by suckling pups, but on the basis of the excitation of sensitive hair receptor responses from 


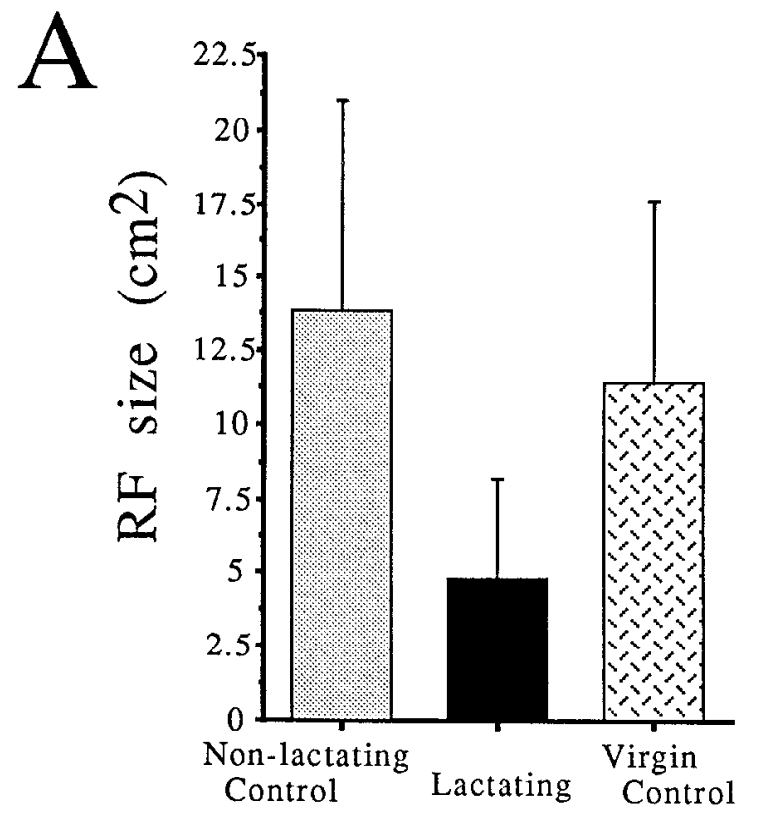

B

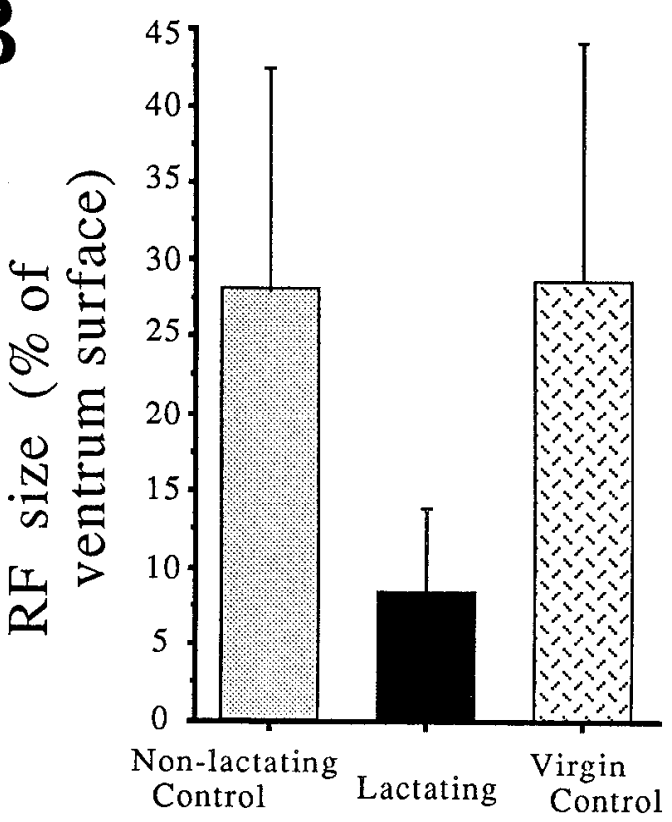

Figure 8. A, RF size means and SDs from the ventrum trunk representational zones in postpartum nonlactating (left), lactating (center), and virgin (right) rat groups. Data from the $+6 \mathrm{~d}$ postpartum rat is included in this analysis as it is not significantly different from the data from the other four postpartum rats, and except for the consequences of an increase in $n$, its inclusion has no important impacts on these statistics. Error bars are SDs. $B$, RF sizes for these three populations, normalized with reference to total ventrum skin area.

the fur surrounding the nipple, given the muzcle contact and the treading of pups on the nearby skin (Wakerley and Drewett, 1975). In practice, any specific inputs evoked from glabrous skin during normal suckling would be difficult to distinguish from those derived from the surrounding hairy skin. In any event, in the small number of samples in which artificial vigorous suction stimuli were applied exclusively to extended nipples, no strong neuronal responses were evoked in this SI ventrum representational zone.
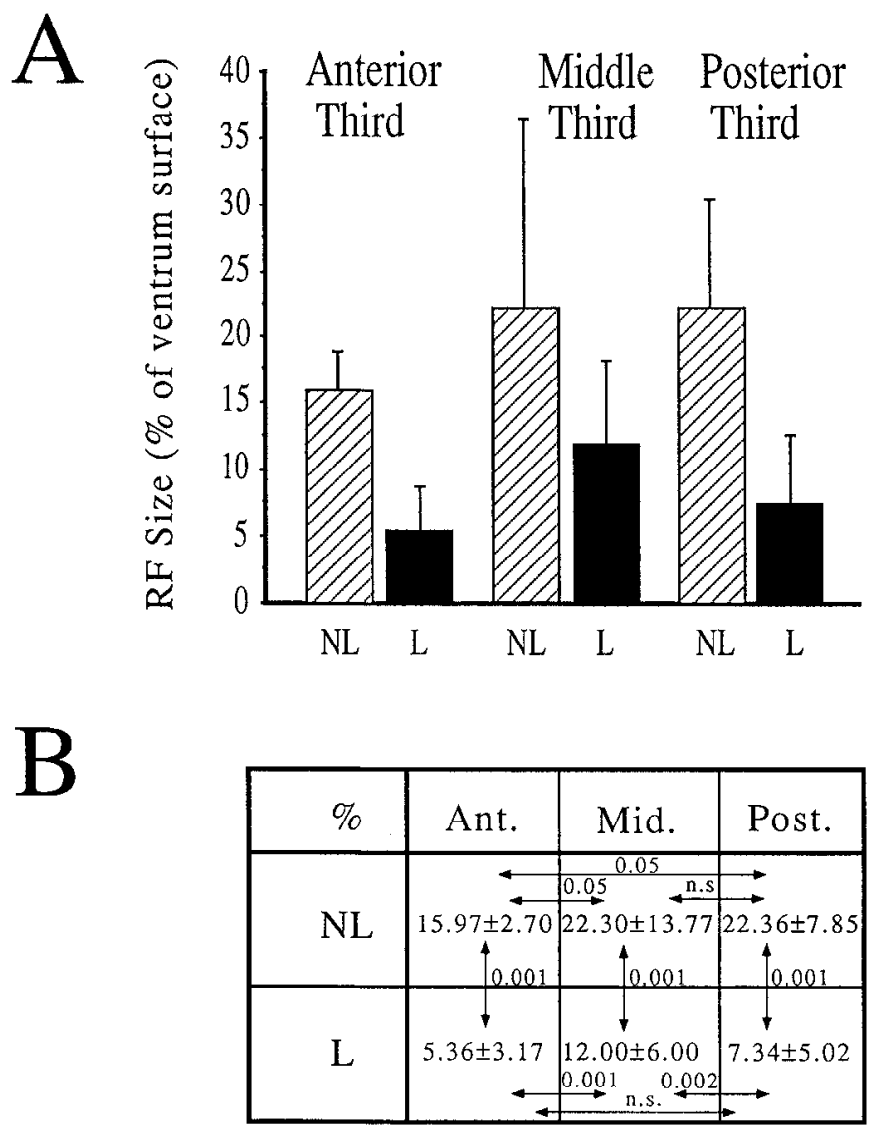

Figure 9. A. Normalized RF areas centered over the anterior, middle, and posterior thirds of the ventrum. Normalization was with respect to the measured total area of the ventrum surface. Data are from postpartum nonlactating $(N L)$ rat series (cross-hatched), and lactating $(L)$ rats (solid). RFs that extensively overlapped two or occasionally three of the skin zones were not included in the analysis. $B$, Statistical summary of RF area differences between lactating and postpartum nonlactating rats.

\section{Two special controls: early postlactation, late postweaning}

Two additional special cases were studied in detail in this series. One lactating rat was examined $6 \mathrm{~d}$ after initiation of lactation, and a second, 2.5 months after weaning that followed a 2-weeklong nursing period. Unfortunately, the ventrum skin was not completely mapped in either individual, so no certain conclusions can be drawn about the SI territories of representation of the ventrum in these cases. Ilowever, a large RF sample in both cases revealed that (1) RFs in the ventrum zone of the $+6 \mathrm{~d}$ postpartum female had a mean area of $3.36 \mathrm{~cm}^{2}(8 \%$ of the ventrum surface), which closely matched those recorded for the other longer term lactating rats in this series; (2) by contrast, RFs in the postweaning rat had a mean area of $9.0 \mathrm{~cm}^{2}(16.8 \%$ of the ventrum), which approached that of control groups. These results indicate that major RF changes have emerged by $6 \mathrm{~d}$ after nursing onset, and that at least this aspect of nursinginduced changes reversed to approach the condition of control rats after a 2.5 -month-long weaning period.

\section{Representation of the trunk dorsum in lactating versus control rats}

The dorsum was completely mapped in two rats in each of the three experimental groups. Dorsum RFs were significantly 


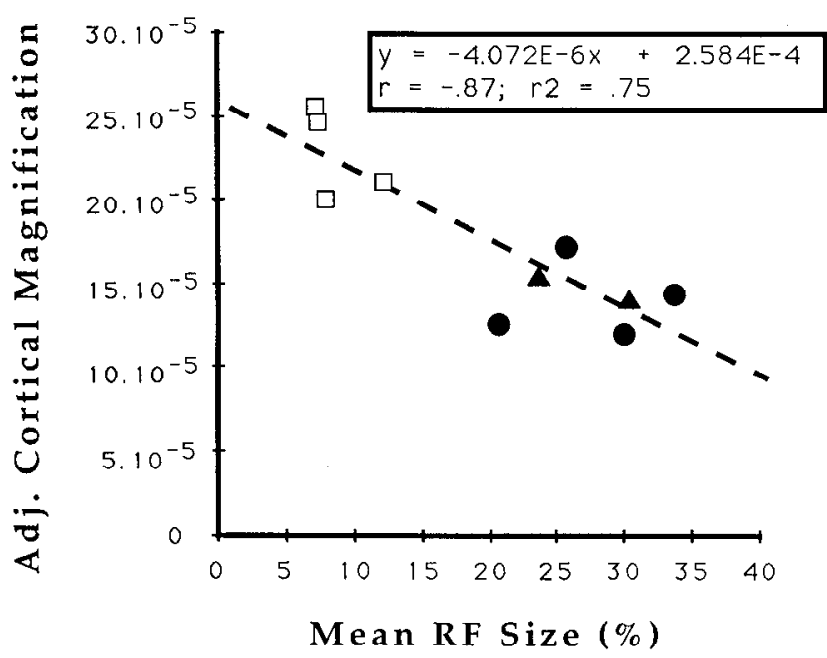

Figure 10. SI cortical magnification (= cortical representational area/ adjusted ventrum skin area) plotted as a function of the mean normalized RF size. Open squares represent lactating female cases; solid circles are from nonlactating controls; solid triangles are from virgin rats. The dashed line is the best-fit straight line. Note that in defining cortical magnification, the stretching of the ventrum skin, largely due to the development of the underlying mammary glands, is compensated for by using measures of the nonexpanded ventrum skin from malched virgin controls, for all three experimental groups. Mean RF areas were also normalized with reference to the total ventrum area. See the text for a justification of these adjustments.

smaller in lactating and nonlactating rats than in virgins. At the same time, no significant differences in dorsum RF sizes were recorded between postpartum nonlactating controls and lactating females.

\section{Discussion}

With the onset of suckling, the ventral skin surfaces of a lactating female rat are subjected to a heavy schedule of differential skin stimulation. These experiments indicate that as an apparent consequence, the SI representation of the nipple-bearing skin of the anterior and posterior ventrum in the Norway rat expands about twofold in area for cortical maps derived 10-19 d after nursing onset. In parallel, RFs representing these differentially stimulated skin surfaces are reduced to about one-third of their control sizes. Thus, the regions of the ventrum skin surfaces surrounding the nipples that are most heavily stimulated in suckling come to be represented in finer topographic grain. These cortical representational differences are plausibly related to gains in sensitivity, sensation magnitudes, and tactile acuity (see Merzenich et al., 1990a,b; Recanzone et al., 1992c,d; W. M. Jenkins and M. M. Merzenich, unpublished observations).

We conclude that the initiation of this epochal regional change in skin inputs results in the emergence of central representational changes that presumably become an intrinsic part of nursing behavior. By that view, this complex behavior is initiated mainly reflexly (Stern, 1990, 1991; Stern and Johnson, 1990; Stern et al., 1992), but with reorganization of central representations of the ventrum induccd by the bchavior, an overlay of adaptive changes consequent from suckling, treading, and other related stimulation evolves that contribute to the sensations and perceptions that are a main aspect of nursing. Changes in SI probably also occur in the zone of representation of the snout and vibrissae, inputs from which have also been demonstrated to be important for aspects of maternal behavior (Kenyon et al.,
1981, 1983; Stern and Kolunie, 1989, 1991; Morgan et al., 1992).

It should be emphasized that these SI changes are likely paralleled by more dramatic representational changes that apply to the central representation(s) of the nipple and areolae. Their skin is not well represented-clearly, not predominantly represented-in the SI cortical field. It has been demonstrated that afferent inputs from the glabrous skin of the nipples and areolae pass into the lateral columns and not the dorsal columns that ultimately provide the main inputs to SI cortcx (Fukuoka et al., 1984; Dubois-Dauphin et al., 1985; Poulain and Wakerley, 1986; Tasker et al., 1986; Wakerley et al., 1988). The cortical destination(s) of this input is unknown. Whatever its subcortical and cortical terminus, it is highly likely that nipple/areolar representations undergo a representational transformation as a consequence of the dramatic differences in afferent inputs from the nipples that result from the onset of suckling.

\section{Some methodological precautions}

Possible contributions of pre-and postnatal changes in skin mechanics and receptor sensitivity. In humans, there is an almost immediate postpartum increase in the sensitivity of both the glabrous and hairy skin of the breast, regardless of whether or not breast feeding occurred, that is argued to be due to the dramatic decline in hormone levels at parturition (Robinson and Short, 1977). These sensitivity changes progress for at lcast $4 \mathrm{~d}$ following nursing onset; skin sensitivity over longer postpartum times has not been examined. Whether "immediate" hypothetically hormonal effects are direct or only reflect changes in skin mechanics is unknown. Changes in the sensitivity and the dynamic ranges of skin afferents would be a possible consequence of increased skin tension and resistance, for example, as the breasts become engorged (Vorheer, 1974), and such differences as well as possible direct hormonal affects on skin mechanics and skin receptors (see Kow and Pfaff, 1973; Adler et al., 1977; Bereiter and Barker, 1980; Bereiter et al., 1980) might well contribute to the very rapid remodeling of cortical representations that follow. On the other hand, (1) no very obvious differences in skin sensitivity or response magnitudes were recorded on the ventrum of lactating rats as compared with nonlactating or virgin controls; (2) the hairy skin over the mammae of lactating females was actually relatively flaccid; (3) hormonal effects in nonlactating rats are identical to those in lactating rats through the time of parturition, and the skin of postpartum nonlactating females expanded significantly, while cortical representations and relative RF sizes in this nonlactating postpartum control population were virtually indistinguishable from those in matched virgin rats; (4) if RF differences were attributable to changes in response scnsitivity alone, then RFs would be expected to be larger in size in the more sensitive lactating females-not smaller-as is the case; (5) peripheral estrogen effects are interpreted to apply generally to all body skin (Bereiter and Barker, 1975, 1980; Bereiter et al., 1980)-in our experiments, differences in cutaneous RF sizes were significant only for the ventrum skin; RFs on the flank and dorsum of the trunk were not different in lactating and control rats; (6) no mere change in afferent sensitivity alone can account for a topographically ordered representational expansion necessitating a pointby-point redefinition of RFs for cortical neurons all across the ventrum SI representational zone.

Thus, while changes in receptor sensitivity may contribute to the rapidity and magnitude of these changes, cortical represen- 
lational remodeling driven by differentially heavy stimulation of the skin overlying the mammary glands is the probable primary cause of them.

Increase of ventrum skin area. With prepartum body weight gains in pregnancy, and with the postpartum development of the mammae, the ventrum skin surface expands in area by about $50 \%$. How does this skin expansion relate to the representational changes recorded in the cortex? We can assume that afferents continue to innervate the same hair follicles over a dimensionally expansible skin surface. In that case, skin expansion alone would be expected to result in proportionally larger-not smaller-central RFs. Such "expansion" also occurs in nonlactating postpartum control females. In any event, when RFs were normalized with reference to the ventrum skin surface area, RFs in those control females were indistinguishable from those in virgin controls, while before this correction for skin expansion, they were significantly larger, in exact proportion to the ballooning of their ventra.

While the expansion of the ventrum skin in lactating rats is paralleled by an increase in its territory of representation in the cortex, this ballooning of the skin does not appear to be the main dependent variable underlying cortical representational enlargement, as: (1) There was also a significant expansion of the ventrum skin of postpartum nonlactating controls, but without nursing, no parallel SI cortical representational change occurred. (2) The skin over the central third of the ventrum appears to balloon as much as does the skin in the posterior and anterior thirds, yet representational changes for this sector did not differ significantly from controls with smaller ventra, and RF changes were modest in this region when compared to those for nipplebearing skin zones. (3) Basic innervation patterns of the skin should be proportionately constant throughout skin expansion. The expanded ventrum skin in lactating females should be innervated by a set of first-order skin afferents that is identical to those that innervated the same (then nonexpanded) skin before pregnancy.

Limitations of these experimental cortical mapping procedures. We have earlier analyzed the magnitudes of errors for estimating representational territories by these mapping and reconstruction methods (see Stryker et al., 1987). The errors in estimating territories of representation are a function of sample densities and the numbers of sites at which representational boundaries are defined. Given the grain of sampling and the numbers of samples within the ventrum zone achieved in the present experiments, there is a less than $10 \%$ error for estimations of SI ventrum zones in these cases.

RFs were defined partly on the basis of subjective response criteria, and often by recording from multiplc unit clustcrs. In validation of these procedures: (1) Very equivalent RF sizes and dispersions were defined by different experimentors in the same rat experiments, and by different experimentors who defined receptive fields in different rat members of the same experimental group. (2) When single units were discriminable in the record, their RFs were usually little different from those of other units in the "cluster." That is a general finding for recording in deep layer 3 (see Stryker et al., 1987; Chapin and Lin, 1990). (3) Recording conditions were identical in lactating and control rat series. (4) Proportionate differences defined in representational areas and RF sizes in the anterior, middle, and posterior thirds of the ventrum were not recognized until after all experiments were completed. The subsequent revelation of these highly consistent regional differences validates the repeatability and accuracy of RFs localization and delimitation procedures.

\section{Differential changes for the representation of nipple-bearing ventrum skin}

Rat pups spend the great majority of their time centered on the nipples, and provide much weaker excitation of the midvcntrum nipple-free region (Stern et al., 1992). In fact, that skin is commonly folded and is less accessible in the typical high upright, crouched position (Stern and Johnson, 1990). Even when the dam is lying down while nursing, the pups are on the nipples. The disproportionate consequences for the representations of the nipple-bearing skin between the forelegs and hindlegs may simply reflect differences in the overall weights of inputs generated from these different skin surfaces in nursing behavior. It is also possible that these representational differences for nipplebearing and non-nipple-bearing ventrum skin are exaggerated by the fact that cortical plasticity is dependent upon the behavioral significance of inputs (Disterhoft et al., 1975; Woody and Engel, 1975; Weinberger and Diamond 1988; Jenkins et al., 1990; Ahissar et al., 1992; Recanzone et al., 1992c,d). That is, if the dam selectively attends to inputs that are associated with suckling, that might further amplify their specific effects for generating representational change in SI.

\section{Some earlier studies on a possible cortical role in nursing behavior}

Beach (1937) found that large lesions of the neocortex are detrimental to performance of maternal behavior. Lesions to the anterior half of the neocortex generated greater deficits than did more posterior lesions. At the same time, the degree of impairment was more strongly related to lesion size than to its specific location. In later studies, investigators focused on the consequences of inducing restricted limbic system lesions, including cingulate cortex lesions (for reviews, see Slotnick, 1967; Numan, 1988; Stern, 1989). Among many other findings, these studies demonstrated a probable role of the medial preoptic nucleus in the regulation of maternal behavior (Numan, 1988), and demonstrated connections of this nucleus with the SI cortical field (Simerly and Swanson, 1988).

It should be remembered that in the present experiment we have only examined experimental changes generated within a single cortical area. As noted earlier, changes must be driven by-and must contribute to-this dramatically emergent behavior within many cortical fields and within several behavioral domains. It is not surprising, then, that nursing behavior can be perturbed by selective lesions that do not include the SI cortex (Beach, 1937). A detailed behavioral assessment beyond that commonly applied in studies of the effects of cortical lesions on nursing behavior, combined with highly selective field-specific lesions-for example, destroying the ventrum representation of SI-will be required to determine how different cortical areas that are remodeled by this behavior contribute to different facets or it.

Several other studies indicate that some aspects of maternal behavior might be learned, and might therefore involve changes in forebrain representations. Thus, for example, the speed of retrieval of pups is greatly decreased with experience (Beach and Jaynes, 1956; Stern and Kolunie, 1989), the latency before milk injection decreases at longer postpartum times (Jans and Wood- 
side, 1987), and maternal behavior is remembered by an experienced female (Bridges, 1975; Fleming et al., 1990). Indeed, long-term retention of maternal responsiveness requires somatosensory contact with pups via either the snout or ventrum (Morgan et al., 1992). Possible contributions of altered cortical representations to these and to many other postpartum phenomena remain to be determined.

\section{Some functional implications: general conclusion}

These observations are consistent with the conclusion that cortical representations of the skin surfaces are remodeled by our experiences throughout life. By this view, any epochal change in behavior results in changes in representational constructs that account for aspects of its evolution. In the case of nursing, powerful hormonal and reflexive changes drive physical changes that enable and encourage the initiation of suckling. Once suckling is begun, the heavy schedule of novel afferent inputs that it generates produces representational changes that presumably alter the sensations and perceptions generated by suckling. These experience-driven neurological changes become an intrinsic part of the behavior, contributing to its character, maintenance, and maturation.

It should be again emphasized that changes induced in the primary somatosensory (SI) representation reconstructed in these experiments constitute only a small piece of the forebrain changes that are doubtless induced by this behavior. In other experiments in behaviorally trained monkeys, we have recorded experience-induced changes in every mapped somatosensory and motor representational area (Merzenich et al., 1990b). Indeed, alteration of the true primary somatosensory field, area $3 \mathrm{~b}$, can be modest in comparison with representational changes generated in other somatosensory representations (see Merzenich, $1990 \mathrm{~b}$; Recanzone et al., 1992b). It is probable that human lactation, for example, results in substantial representational remodeling in most or all of more than 10 different somatosensory representational areas, as well as in a number of motor and premotor zones. Moreover, if inputs from the nipples and areolae are segregated from the representation of the surrounding hairy skin in primates as in rats, a second set of forebrain areas are likely to be substantially altered in their representation of this behaviorally important skin, on at least an equivalent scale.

This study constitutes only the beginnings, then, of an effort to reconstruct the complex, distributed, changes that evolve with maternal behavior. Their elucidation should deepen our understanding of the neurological bases and the ontogeny of this complex epochal behavior. A similar adaptive neurology underlies the genesis and maturation of all new behaviors, which are similarly subject to reconstructive elucidation.

\section{References}

Adler NT, Davis P, Komisaruk BR (1977) Variation in the size and sensitivity of a genital sensory field in relation to the estrous cycle in rats. Horm Behav 9:334-344.

Ahissar E, Vasdia E, Ahissar M, Bergman H, Arieli A, Abeles M (1992) Dependence of cortical plasticity on correlated activity of single neurons and on behavioral context. Science 257:1412-1415.

Beach FA (1937) The neural basis of innate behavior. J Comp Neurol 24:334-344.

Beach FA, Jaynes J (1956) Studies on maternal retrieving in rats. II. Cffects of practice and previous parturitions. Am Nat 90:103-109.

Bereiter DA, Barker DJ (1975) Facial receptive fields of trigeminal neurons: increased size following estrogen treatment in female rats. Neuroendocrinology 18:115-124.

Bereiter DA, Barker DJ (1980) Hormone-induced enlargement of re- ceptive fields in trigeminal mechanoreceptive neurons. I. Time course, hormone, sex and modality specificity. Brain Res 184:395-410.

Bereiter DA, Stanford LR, Barker DJ (1980) Hormone-induced enlargement of receptive fields in trigeminal mechanoreceptive neurons. II. Possible mechanisms. Brain Res 184:411-423.

Bridges RS (1975) Long-term effects of pregnancy and parturition upon maternal responsiveness in the rat. Physiol Behav 14:245-250.

Chapin JK, Lin C-S (1984) Mapping of the body representation in the SI cortex of anesthetized and awake rats. J Comp Neurol 229:199_ 213.

Chapin J, Lin C-S (1990) The somatic sensory cortex of the rat. In: The cerebral cortex of the rat (Kolb B, Tecs RC, cds), pp 341-380. Cambridge, MA: MIT Press.

Delacour J, Houcine M, Talbi B (1987) "Learned" changes in the responses of the rat barrel field neurons. Neuroscience 23:63-71.

Disterhoft JF, Olds J (1972) Differential development of conditioned unit changes in thalamus and cortex of rat. J Neurophysiol 35:665679.

Dubois-Dauphin M, Armstrong WE, Tribolet E, Driefuss JJ (1985) Somatosensory systems and the milk-ejection reflex in the rat. II. The effects of lesions of the ventroposterior thalamic complex, dorsal columns and lateral cervical nucleus-dorsolateral funiculus. Neuroscience 15:1131-1140.

Edelman GM (1987) Neuronal Darwinism: the theory of neuronal group selection. New York: Basic.

Fleming AS, Cheung US, Barry M (1990) Cyclohexamide blocks the retention of maternal experience in postpartum rats. Behav Neural Biol 53:64-73.

Fukuoko T, Negoro H, Honda K, Higuchi T, Nishida E (1984) Spinal pathway for the milk-ejection reflex. Biol Reprod 30:74-81.

Grota LJ, Ader R (1969) Continuous recording of maternal behavior in Rattus norvegicus. Anim Behav 17:722-729.

Grota LJ, Ader R (1974) Behavior of lactating rats in a dual-chambered maternity cage. Horm Behav 5:275-282.

Holloway WR, Dollinger MJ, Denenberg VH (1980) Parturition in the rat: description and assessment. In: Maternal influences and early behavior (Bell RW, Smotherman WP, eds), pp 1-26. New York: Medical Science Books.

Hubel DH, Wiesel TN (1974) Uniformity of monkey striate cortex: a parallel relationship between ficld size, scatter and magnification factor. J Comp Neurol 158:295-302.

Jans JE, Woodside B (1987) Effects of litter age, litter size, and ambient temperature on the milk ejection reflex in lactating rats. Dev Psychobiol 20:333-344.

Jenkins WM, Merzenich MM, Ochs MT, Allard T, Guic-Robles E (1990) Functional reorganization of primary somatosensory cortex in adult owl monkeys after behaviorally controlled tactile stimulation. J Neurosci 63:82-104.

Kenyon P, Cronin P, Keeble S (1981) Disruption of maternal retrieving by perioral anesthesia. Physiol Behav 27:313-321.

Kossut M (1992) Plasticity of the barrel cortex neurons. Prog Neurobiol 39:389-422.

Kossut M, Hand PJ, Greenberg J, Hand CL (1988) Single vibrissal cortical column in SI cortex of rat and its alterations in nconatal and adult vibrissa-deafferented animals: a quantitative $2 D G$ study. J Neurophysiol 60:829-852.

Kow L, PfafT DW (1973) Efrects of estrogen treatment on the size of receptive field and response threshold of pudendal nerve in the female rat. Neuroendocrinology 13:299-313.

Leon M, Croskerry PG, Smith GK (1978) Thermal control of motheryoung contact in rats. Physiol Behav 21:793-811.

Merzenich MM, Sameshima K (1993) Cortical plasticity and memory. Curr Opin Neurobiol 3:187-196.

Merzenich MM, Kaas JH, Wall JT, Nelson RJ, Sur M, Fellerman DJ (1983) Progression of change following median nerve section in the cortical representation of the hand in areas $3 b$ and 1 in adult owl and squirrel monkeys. Neuroscience 10:639-665.

Merzenich MM, Jenkins WM, Middlebrooks JC (1984a) Observations and hypothesis on special organization features of the central auditory nervous system. In: Dynamic aspects of neocortical function (Edelman G, Gall E, Cowan M, eds), pp 397-424. New York: Wiley.

Merzenich MM, Nelson RJ, Stryker MP, Cynader MS, Schoppmann A, Zook JM (1984b) Somatosensory cortical map changes following digit amputation in adult monkeys. J Comp Neurol 224:591-605.

Merzenich MM, Recanzone G, Jenkins WM, Allard T, Nudo RJ (1988) 
Cortical representational plasticity. In: Neurobiology of neocortex (Rakic P, Singer W, eds), pp 42-67. New York: Wiley.

Merzenich MM, Recanzone GH, Jenkins WM, Grajski KA (1990a) Adaptive mechanisms in cortical networks underlying corlical contributions to learning and nondeclarative memory. Cold Spring Harbor Symp Quant Biol 55:873-887.

Merzenich MM, Recanzone GH, Jenkins WM, Nudo RJ (1990b) How the brain functionally rewires itself. In: Natural and artificial parallel computations (Arbib M, Robinson J, eds), pp 177-210. Cambridge, MA: MIT Press.

Morgan HD, Fleming AS, Stern JM (1992) Somatosensory control of the onset and retention of maternal responsiveness in primiparous Sprague-Dawley rats. Physiol Behav 51:549-555.

Numan M (1988) Maternal behavior. In: The physiology of reproduction (Knobil E, Neill J, eds), pp 1569-1645. New York: Wiley.

Poulain DA, Wakerley JB (1986) Afferent projections from the mammary glands to the spinal cord in the lactating rat. II. Electrophysiological responses to spinal neurons during stimulation of the nipples, including suckling. Neuroscience 19:511-521.

Recanzone GH, Merzenich MM, Jenkins WM, Grajski KA, Dinse HR (1992a) Topographic reorganization of the hand representation in cortical area $3 \mathrm{~b}$ of owl monkeys trained in a frequency-discrimination task. J Neurophysiol 65:1031-1056.

Recanzone GH, Merzenich MM, Jenkins WM (1992b) Frequency discrimination training engaging a restricted skin surface results in an emergence of a cutaneous response zone in cortical area $3 \mathrm{a} . J$ Neurophysiol 65:1057-1070.

Recanzone GH, Merzenich MM, Schreiner CE (1992c) Changes in the distributed temporal response properties of SI cortical neurons reflect improvements in performance on a temporally based tactile discrimination task. J Neurophysiol 67:1071-1091.

Recanzone GH, Schreiner CE, Merzenich MM (1992d) Plasticity in the frequency representation of primary auditory cortex following discrimination training in adult owl monkeys. J Neurosci 13:87-103.

Robinson JE, Short RV (1977) Changes in breast sensitivity at puberty, during the menstrual cycle, and at parturition. Br Med J 1:11881191.

Rosenblatt JS, Lehrman DS (1963) Maternal behavior of the lactating rat. In: Maternal behavior in mammals (Rheingold $\mathbf{H}$, ed), pp 8-56. New York: Wiley.

Roth L, Rosenblatt JS (1967) Changes in self-licking during pregnancy in the rat. J Comp Physiol Psychol 63:397-400.

Roth L, Rosenblatt JS (1968) Self-licking and mammary development during pregnancy in the rat. J Endocrinol 42:363-378.

Simerly RB, Swanson LW (1988) Projections of the medial preoptic nucleus: a Phaseolus vulgaris leucoagglutinin anterograde tract-tracing study in the rat. J Comp Neurol 260:209-242.

Slotnick BM (1975) Neural and hormonal basis of maternal behavior in the rat. In: Hormonal correlates of behavior: an organismic view (Eleftheriou BE, Sprott RL, eds), pp 585-656.

Stern JM (1989) Maternal behavior: sensory, hormonal, and neural determinants. In: Psychoendocrinology (Brush FR, Levine S, eds), pp 105-226. New York: Academic.

Stern JM (1990) Multisensory regulation of maternal behavior and masculine sexual behavior: a revised view. Neurosci Behav Rev 14: 183-200.

Stern JM (1991) Nursing posture is elicited rapidly in maternally naive, haloperidol-treated female and male rats in response to ventral trunk stimulation from active pups. Horm Behav 25:504-517.

Stern JM, Johnson SK (1990) Ventral somatosensory determinants of nursing behavior in Norway rats. I. Effects of variations in the quality and quantity of pup stimuli. Physiol Behav 47:993-1011.

Stern JM, Kolunie JM (1989) Perioral anesthesis disrupts maternal behavior during early lactation in Long-Evans rats. Behav Neural Biol 52:20-38.

Stern JM, Kolunie JM (1991) Trigeminal lesions and maternal behavior in Norway rats: I. Effects of cutaneous rostral snout denervation on maintenance of nurturance and maternal aggression. Behav Neurosci 105:591-596.

Stern JM, Levin R (1976) Food availability as a determinant of the rats' circadian rhythm in maternal behavior. Dev Psychobiol 9:137148.

Stern JM, Taylor LA (1991) Haloperidol inhibits maternal retrieval and licking, but enhances nursing behavior and litter weight gains in lactating rats. J Neuroendocrinol 3:591-596.

Stern JM, Dix L, Bellomo C, Thramann C (1992) Ventral trunk somatosensory determinants of nursing behavior in Norway rats. 2 . Role of nipple and surrounding sensations. Psychobiology 20:71-80.

Stryker MP, Jenkins WM, Merzenich MM (1987) Anesthetic state does not affect the map of the hand representation within area $3 b$ somatosensory cortex in owl monkey. J Neurophysiol 44:295-311.

Sur M, Merzenich MM, Kaas JH (1980) Magnification, receptive-field area, and "hypercolumn" size in areas $3 \mathrm{~b}$ and 1 of somatosensory cortex in owl monkeys. J Neurophysiol 44:295-311.

Tasker JG, Theodosi DT, Poulain DA (1986) Afferent projections from the mammary glands to the spinal cord in the lactating rat. I. A neuroanatomical study using the transganglionic transport of horseradish peroxidase-wheatgerm agglutinin. Neuroscience 19:495-509.

Tucker HA (1988) Lactation and its hormonal control. In: The physiology of reproduction (Knobil E, Neill J, eds), pp 2235-2264. New York: Wiley.

Voloschin LM, Tramezzani JH (1979) Milk ejection reflex linked to slow wave sleep in nursing rats. Endocrinology 99:49-58.

Vorheer H (1974) The breast: morphology, physiology and lactation. New York: Academic.

Wakerley JB, Drewett RF (1975) Pattern of sucking in the infant rat during spontaneous milk ejection. Physiol Behav 15:277-281.

Wakerley JB, Clarke G, Summerlee AJS (1988) Milk ejection and its control. In: The physiology of reproduction (Knobil E, Neill J, eds), pp 2283-2321. New York: Wiley.

Weinberger NM, Diamond DM (1988) Dynamic modulation of the auditory system by associative learning. In: Auditory function: neurobiological bases of hearing (Edelman G, Hassler S, Gall E, eds), pp 485-502. New York: Wiley.

Welker C (1971) Microelectrode delineation of fine grain somatotopic organization of SmI cercbral ncocortex in albino rat. Brain Res 6:259276.

Welker C (1976) Receptive fields of barrels in the somatosensory neocortex of the rat. J Comp Neurol 166:173-188.

Welker E, Rao SB, Dorf J, Melzer P, van der Loos H (1992) Plasticity in the barrel cortex of the adult mouse: effects of chronic stimulation upon deoxyglucose uptake in the behaving animal. J Neurosci 12 : 153-170.

Woody CD, Engel J Jr (1972) Changes in unit activity and thresholds to electrical microstimulation at coronal-pericruciate cortex of cat with classical conditioning of different facial movements. J Neurophysiol 35:230-241

Yun JT, Merzenich MM, Woodruff T (1987) Alteration of functional representations of vibrissae in the barrel field of adult rats. Soc Neurosci Abstr 13:1596. 